\title{
Cartografias possíveis: um olhar sobre os mapas mentais indígenas em Rondônia, Brasil
}

Alex Mota dos Santos ${ }^{1}$

\begin{abstract}
Resumo
O mapa é sem dúvida o recurso mais aceito e difundido para representação espacial. Contudo, sua aceitação só ocorre de forma plena quando elaborados a partir de rigores de um método. No entanto, outras cartografias são possíveis a partir dos mapeamentos participativos. Diante de tal possibilidade, o objetivo dessa análise é revelar outras cartografias a partir dos mapas mentais indígenas e apontar para seu uso no processo de ensino-aprendizagem. A metodologia contemplou o estudo de caso, a observação em campo e a análise empírica e empregou-se a Metodologia Kozel para estudo dos mapas mentais. Os resultados revelaram as potencialidades no ensino e reconhecimento dos conflitos, reinvindicações do território, relações de parentesco, estudo do meio físico, impactos ambientais sobre as terras indígenas e sobre a fauna e flora.
\end{abstract}

\section{Palavras-chave}

Mapas Mentais. Conhecimentos Tradicionais. Processo EnsinoAprendizagem. Rondônia.

1. Doutor em Geografia pela Universidade Federal do Paraná; professor adjunto da Universidade Federal de Goiás, Campus Aparecida de Goiânia, Brasil. E-mail: alex.geotecnologias@gmail.com. 


\title{
Possible cartographies: a look on indigenous mental maps in Rondônia State, Brazil
}

Alex Mota dos Santos*

\begin{abstract}
Maps are with no doubts the most accepted and disseminated resource for spatial representation. However, their acceptance is only complete when prepared under the rigors of a cartography method. Also, others cartographies are possible from participatory mapping. Thus, from this possibility the purpose of this analysis is to reveal other cartographies from indigenous mental maps and to indicate its use in the teaching and learning process. The methodology included the case study, in loco observation, comparison and empirical analysis and used the Kozel Methodology for the study of mental maps. The results revealed the potential in learning and recognition of the conflicts, the territory claim, family relationships, study of the physical environment, environmental impacts on indigenous lands and on animals and vegetation.
\end{abstract}

\section{Keywords}

Mental Maps. Traditional Knowledge. Teaching and Learning Process. Rondônia State.

* PhD in Geography, Federal University of Paraná, State of Paraná, Brazil; assistant professor at Federal University of Goiás, Campus Aparecida de Goiânia, State of Goiás, Brazil. E-mail: alex.geotecnologias@gmail.com. 


\section{Introdução}

O mapa é um importante instrumento de ensino e ocorre por meio da Cartografia. Não é o único produto, mas, certamente, é o mais difundido por essa área do conhecimento. Além disso, os mapas são importantes não só para a Cartografia, pois é reconhecido seu uso e potencial nas diversas áreas do conhecimento. Estudos com mapas podem estar presentes no ensino de assuntos variados, especialmente a partir da valorização da "visualização espacial dos temas, que acontece através das representações cartográficas" (LOCH; FUCKNER, 2003, p. 2).

Os mapas, como expressão máxima da Cartografia, surgiram e materializaram as experiências humanas no espaço. Nesse sentido, é uma forma de linguagem mais antiga que a própria escrita e notação matemática (HARLEY, 1991). No entanto, ao falarmos de mapa, certamente é recorrente pensarmos em representações elaboradas sob os rigores de um método, preocupado com convenções cartográficas, especialmente aquela ditada pela escola europeia. Nesse sentido, segundo Harley (1991), durante muito tempo a arte de fazer mapa foi considerada essencialmente uma prática dos europeus. Contudo, é reconhecida no período mais recente como uma linguagem visual de todas as civilizações. Com efeito, compreendemos mapa na perspectiva de Harley (1991, p. 7), que o definiu "como um instrumento de representação que facilita a compreensão espacial de objetos, conceitos, condições, processos e fatos do mundo humano". A representação, segundo este autor, perpassa a cartografia humanista por estar presente na cultura humana, embora raramente reconhecida e valorizada.

A partir de tal possibilidade sugerimos o termo "mapas humanistas", apesar de, na tradição humanista, os mapas não serem necessariamente impressões no papel e serem melhores entendidos como processos e não como produtos (RUNDSTROM, 1991). Contudo, a característica marcante dos mapas que nos permite designá-los como "humanistas" advém do fato de que eles privilegiam saberes tradicionais, no caso em estudo, dos povos indígenas, e retratam o ser no mundo. $\mathrm{E}$ isso contribui para a consideração do saber tradicional que é negado pelo não indígena e tratado com atitudes etnocêntricas.

Nessa vertente, valoriza-se a participação de grupos sociais e dos processos socioambientais e econômicos, considerando sua dimensão cultural. A partir dessa perspectiva, e ao ampliar o conceito de mapa, reconhecemos o potencial dos mapas mentais, inclusive no processo de ensino-aprendizagem pelos povos indígenas que possuem conhecimento profundo do espaço, fato que aumenta a habilidade espacial e a definição de seus lugares, dos seus territórios e modos de vida. Com efeito, "a habilidade espacial é manifestada em nossa capacidade de libertar-nos dos laços que nos prendem a um lugar, na amplitude e velocidade de nossa mobilidade" (TUAN, 1983, p. 98). Portanto, mapear mentalmente e livremente é uma estratégia de divulgação do saber indígena e uma possibilidade de contribuição para o rompimento de sua "invisibilidade" na sociedade brasileira.

Deste modo, o objetivo deste artigo é revelar as cartografias possíveis a partir dos mapas indígenas e apontar para seu uso no processo de ensino-aprendizagem. Obviamente que, ao sugerir aplicações no ensino, não foi objetivo da pesquisa engessar as possibilidades de aplicações dos mapas indígenas. Cabe ao leitor a tarefa de explorá-los.

A pesquisa foi realizada com professores indígenas, que frequentaram o curso de Licenciatura Básica Intercultural, promovido pela Universidade Federal de Rondônia, Campus de Ji-Paraná, no período de 2011 
a 2014, e foi a primeira a ser analisada em nossa tese de doutoramento em Geografia da Universidade Federal do Paraná. No curso, estavam matriculados 111 professores indígenas de 16 terras indígenas do estado e mais quatro terras que ocupam a área de Mato Grosso.

Do universo da pesquisa, destaca-se o fato de que o estado de Rondônia possui 52 municípios (Figura 1), dos quais 26 possuem parte de suas áreas ocupadas pelas 16 terras indígenas inseridas integralmente no território rondoniense e mais quatro terras que se localizam também em área de outros estados, que juntas cobrem 49.967,01 km².

Figura 1 - Espacialização das terras indígenas de Rondônia.

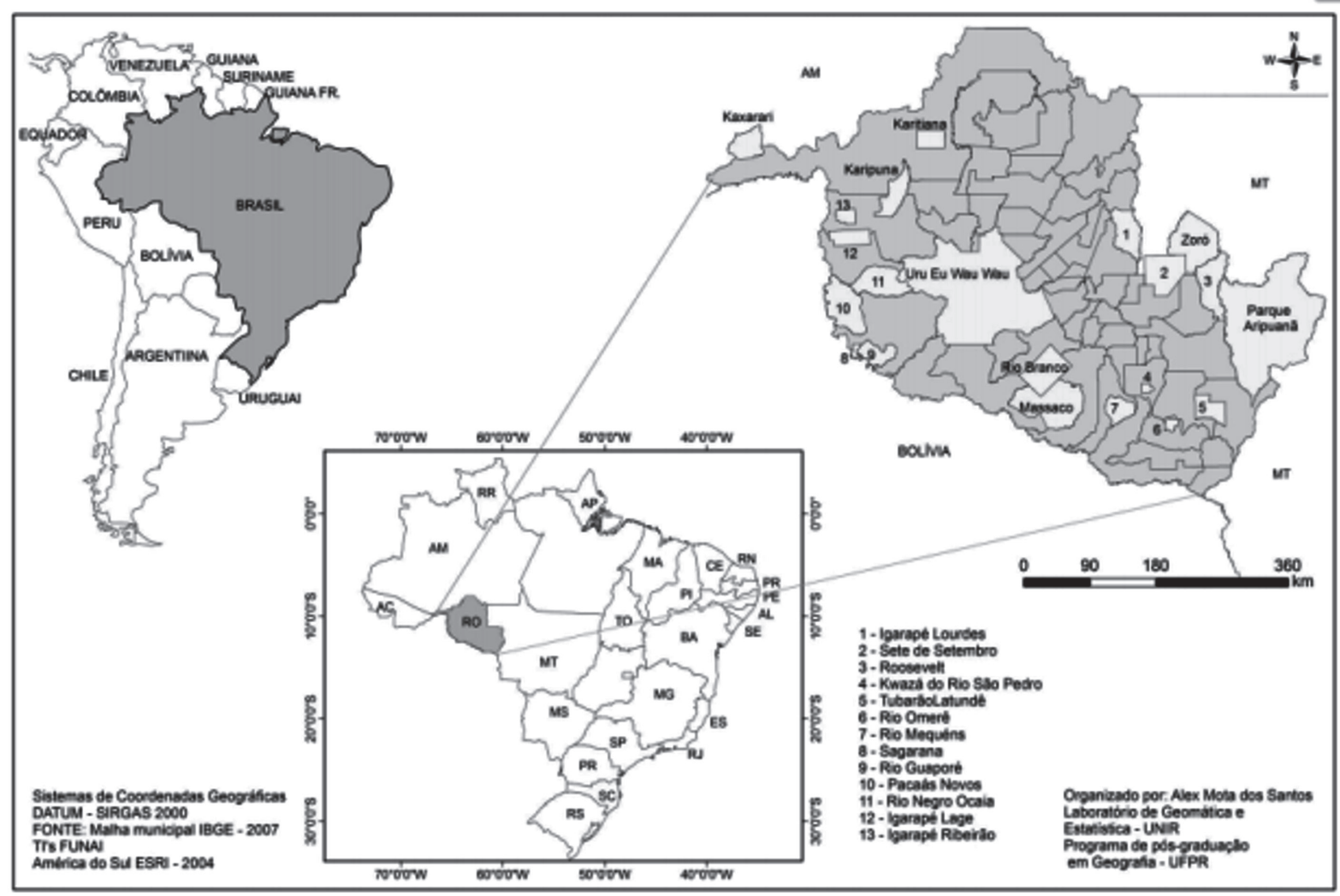

Fonte: O autor (2014).

\section{Considerações teóricas sobre os “mapas humanistas"}

As abordagens do mapa na perspectiva humanista são variadas, destacando os termos "mapas mentais", "mapas cognitivos" e "mapas culturais". O termo mapa mental pode se referir a mind map ou mental map, sendo que
[O] primeiro termo foi sistematizado por Tony Buzan, escritor inglês, que ofereceu um manual de construção de mapa mental na sua obra intitulada "Mapas mentais, métodos criativos para estimular o raciocínio e usar ao máximo o potencial do seu cérebro" e que foi publicado no Brasil no ano de 2009. Referese, assim, à análise psicológica (dinâmicas de grupo em empresas, organização pessoal, por 
exemplo) de forma a explorar o potencial do cérebro. O termo mental map na Geografia foi empregado por Peter Gould e White na sua obra Mental Map. Os autores discutem as preferências espaciais a partir dos mapas mentais. (SANTOS, 2014, p. 102).

O termo mapa cognitivo também é explorado amplamente na literatura, e fundamenta-se na psicologia genética de Jean Piaget (OLIVEIRA, 1978). No Brasil, os estudos cognitivos do mapa foram explorados pelas professoras Gisele Girardi e Lívia de Oliveira. O uso dos mapas cognitivos não é exclusividade de geógrafos. Segundo Castro Aguirre (1999, s.p.),

hoy son además de los geógrafos, los planificadores y arquitectos urbanistas, los sociólogos urbanos, los antropólogos, los hombres de marketing, los neurólogos, los científicos cognitivos, los psicólogos ambientales quienes se interesan por los mapas cognitivos y nos dejan en innumerables escritos sus matices y su enfoque sobre el concepto.

Assim, os dados para os estudos cognitivos não estão nos censos ou em outras fontes, mas sim nas pessoas, na forma como se relacionam com o mundo, incluindo as experiências e memórias (CASTRO AGUIRRE, 1999).

Adicionalmente, segundo Correia e Sá (2009), o termo mapa cognitivo refere-se à representação mental que o indivíduo faz do ambiente que o cerca. Para Oliveira (2009), a cognição é essencialmente egocêntrica e está ligada a certa posição do sujeito percebedor em relação ao objeto, sendo estritamente individual e incomunicável (senão através da linguagem ou do desenho).

Ao estabelecer a comparação entre mapa mental e mapa cognitivo, Castro Aguirre (1999, s.p.) afirma que "el mapa cognitivo alude a un mapa dentro de la mente, cosa que no lo hacía el mapa mental, y el mapa cognitivo alude a una interioridad mental y quiere reflejarlo de una manera fidedigna". Além disso, de acordo com Archela e Archela (2002), a teoria cognitiva como método cartográfico envolve operações mentais lógicas, como comparação, análise, síntese e abstração. Aplicada à Cartografia, tal teoria se preocupa mais com as características do usuário do que com o processo de leitura no qual o mapa passou a ser um instrumento para aquisição de novos conhecimentos sobre a realidade apresentada (SANTOS, 2014).

Por fim, outro material explorado pelos geógrafos da corrente humanista são os mapas sociais. Esse conceito está associado às diversas iniciativas de mapeamento que se propõem a incluir populações locais nos processos de produção de mapas e está disseminado mundialmente desde os anos 1990 (ACSELRAD; COLI, 2008). Ainda, segundo os autores, suas raízes metodológicas estariam ligadas ao que as agências promotoras do desenvolvimento chamaram de "observação participativa" e "metodologias de pesquisa colaborativa".

De acordo com o levantamento realizado por Acselrad e Coli (2008), no ano de 2008, $7,65 \%$ dos mapeamentos participativos foram realizados na forma de etnozoneamentos em terras indígenas, especialmente na Amazônia brasileira. E, nesse sentido, Mendonça Neto (2013) afirma que Cartografia Social consiste na valorização e participação de grupos populacionais na percepção de seu território, pressupondo a compreensão da complexidade dos processos socioambientais e econômicos, sem desconsiderar a dimensão cultural. Depreende-se dessa afirmação que o mapa social está associado ao processo de reivindicação e afirmação de identidade e de território. Geralmente, "os projetos em Cartografia Social valorizam o processo híbrido de mapeamento, ou seja, os mapas são digitalizados sobre imagens orbitais georreferenciadas ou bases cartográficas digitais" (SANTOS, 2014, p. 105).

A partir dessas considerações, dá- 
se um destaque aos mapas elaborados pelos povos indígenas no âmbito do que se convencionou designar de Cartografia Indígena ou Etnocartografia. De modo ser possível constatar que as representações gráficas espaciais indígenas estão amplamente documentadas no Brasil, com destaque para os trabalhos realizados pelos povos indígenas no estado do Acre, no âmbito dos projetos da Comissão Pró-Índio, desde meados da década de 1990 e pelo Instituto Socioambiental (ISA), com os indígenas do Xingu, no ano de 1996. Adicionalmente, citam-se as produções no âmbito dos cursos de Licenciatura Intercultural da Universidade Federal de Rondônia, de Goiás e Minas Gerais, e da Universidade Estadual do Mato Grosso, como exemplos.

De acordo com Chapin, Lamb e Threlkeld (2005), os mapeamentos realizados pelos e para os povos indígenas surgem da preocupação em garantir a posse da terra, gerenciar recursos naturais e fortalecer as culturas. Observamos também a possibilidade de utilizar esses produtos cartográficos como instrumento de ensino. Ainda segundo o autor, o mapeamento elaborado por indígenas é um fenômeno recente, iniciado no Canadá e Alaska, em 1960, e difundido rapidamente pelo mundo.

No entanto, na obra Amerindian maps: the explorer as translator, Barbara Belyea (1992) chama a atenção para o fato de que as convenções cartográficas dos povos indígenas contribuíram para a estruturação de mapas para a exploração europeia. E, assim, apesar de negados pelos europeus, os mapas ameríndios foram consultados para obtenção de informações espaciais desconhecidas.

No Brasil, os mapeamentos para e pelos povos indígenas surgem, em sua grande maioria, para delimitar territórios/territorialidades identitários/as (ACSELRAD; COLI, 2008). Assim, os etnomapas são estruturados majoritariamente para fins específicos de reivindicação territorial, mas também como ferramenta de ensino, especialmente na Geografia (ALMEIDA, 2005; GAVAZZI, 2012).

\section{Abordagens básicas sobre as metodologias de análise de "mapas humanistas"}

O processo de análise e decodificação de mapas aqui denominados "humanistas" é realizado de forma colaborativa; os autores das representações discutem suas produções, contribuindo para um diálogo intercultural. No entanto, foi possível identificar na literatura diversas análises e formas de compreensão dessas representações, isso porque, para Kozel (2007), como construções sígnicas, os mapas mentais requerem uma interpretação/codificação.

Em sua tese, Kashiwagi (2011) apresentou metodologias de análise dos mapas mentais, cognitivos ou culturais evidenciadas por Kevin Andrew Lynch, Lloyd Rodwin, Peter Gould, Gary Trent Moore, Constancio de Castro Aguirre e de Salete Kozel.

Em síntese, a metodologia proposta por Kevin Andrew Lynch contempla a análise dos elementos da cidade e busca na forma da cidade o detalhamento do desenho das ruas, o design de outros elementos, a qualidade da forma, o sentido do todo, a forma metropolitana e o processo de design.

A metodologia de Lloyd Rodwin, também voltada para a análise em ambientes urbanos, levou-o a desenvolver uma metodologia baseada na ideia de que os esboços eram sequenciais (RODWIN, 1969 apud KASHIWAGI, 2011).

O geógrafo Peter Gould foi o responsável pela introdução do termo "carta mental" como sinônimo de mapa mental nos estudos geográficos. A metodologia proposta por ele busca desvendar as imagens que as pessoas têm dos componentes de seu espaço a partir de modelos matemáticos, dos quais a matriz de erro. Depreende-se da leitura da metodologia de Peter Gould que o autor parte do princípio de que 
existe uma "verdade" e que é possível mensurar o quanto uma resposta de seus inquiridos varia em torno dessa "verdade" (SANTOS, 2014).

A metodologia de Gary Trent Moore é baseada na teoria construtivista interacional. Segundo essa teoria, cada pessoa tem "muitos mundos" em suas cabeças que resultam da interação do indivíduo com seu meio (MOORE, 1983). Nessa teoria, a realidade é uma construção, não é dada e não está acabada, pois está sujeita à alteração resultante das interações contínuas. Isso porque, para o autor, as pessoas são organismos ativos que se adaptam ao mundo mediante o conhecimento de mundo e de si mesmas. A metodologia Moore (1983) é estruturada em dois momentos básicos. Inicialmente, pede-se a cada sujeito que estruture mapas da cidade, incluindo o número máximo de lugares conhecidos, e que verbalize o que está desenhando e como decidiu colocar os diferentes elementos. No segundo momento, utiliza-se um desenho experimental entre os sujeitos e se examina outra vez cada sujeito em cada uma das condições (áreas subjetivamente mais e menos familiares em dois conjuntos de provas, desenho de mapas e realização de provas de associatividade e reversibilidade).

A metodologia de Constancio de Castro Aguirre não é exatamente um método, pois parte da contextualização do termo "preferência geográfica" adotado na metodologia de Peter Gould para apontar os espaços familiares e não familiares (KASHIWAGI, 2011). Portanto, sua metodologia envolve análise no âmbito da psicologia matemática e de outras matérias, como estatística, metodologia quantitativa etc. Essa metodologia é quantitativa e está relacionada com as análises científicas que podem ser testadas matematicamente.

Por fim, a metodologia Kozel é amplamente aplicada e serve de referência para inúmeras pesquisas. Ela foi desenvolvida pela professora Salete Kozel em 2001, mas foi resgatada, em nossa pesquisa, a partir de
Kozel (2007). Essa metodologia resulta das interlocuções com a geografia fenomenológica de Eric Dardel (2011) e favorece a compreensão de geograficidade que, entre outros itens, discute: a noção de distância (longe, perto, dentro, fora); a questão da afetividade, dos laços afetivos; as ações e as intenções humanas; e as questões dos limites afetivos.

A partir dessa metodologia os mapas mentais são analisados de acordo com os seguintes quesitos: 1 - Interpretação quanto à forma de representação dos elementos na imagem; 2 -Interpretação quanto à distribuição dos elementos na imagem; 3 - Interpretação quanto à especificidade dos ícones: a) Representação dos elementos da paisagem natural, b) Representação dos elementos da paisagem construída, c) Representação dos elementos móveis; d) Representação dos elementos humanos; 4 - Apresentação de outros aspectos ou particularidades.

A partir da análise visual dos mapas mentais, avança-se para o momento das entrevistas para se desvendar o mundo vivido do indivíduo, as relações de afetividade e os valores simbólicos do lugar representados nas imagens mentais. Nessa associação, identificam-se os elementos sígnicos de maior relevância para a análise. No terceiro momento, os elementos identificados são analisados por meio da teoria linguística de Bakhtin. Nessa fase de análise, geram-se tabelas e gráficos para confrontar os dados e, por fim, compreender a intencionalidade dos significados das imagens.

Diante das possibilidades e observando as potencialidades dos mapas mentais, este trabalho revela as cartografias indígenas e aplicações no ensino a partir dos mapas mentais. Essa possibilidade é defendida por Richter (2011), quando este afirma que o uso do mapa mental é um instrumento valioso de representação espacial e, portanto, de comunicação do raciocínio geográfico. Portanto, todas as áreas do conhecimento que estudam 
o espaço poderão se beneficiar em menor ou maior grau desse recurso cartográfico.

\section{Um olhar sobre os mapas indígenas de Rondônia}

As representações gráficas revelaram o poder dos povos indígenas em gerar símbolos, ícones e índices que, na perspectiva da semiótica, leva o ser à condição de pensante, sensitivo e reativo, possibilitando a compreensão de si mesmo e de seu mundo (SIMÕES, 2014).

Os ícones representam os anseios das comunidades e resultam em símbolos que contribuem para as convenções junto a elas. A partir dessa ação de mapear, muito se descortina do meio, dos mundos e do que mais incomoda os povos indígenas. Além disso, como arte, os mapas indígenas não são limitados, revelam discussões, anseios, além de descortinar as realidades vividas.

Os mapas mentais se apresentaram de forma bidimensional e oblíqua. Os primeiros foram mais orientadores, representaram a percepção de cima e permitiram análises mais facilitadas das relações topológicas dos elementos representados.

Com isso, em síntese, os mapas mentais indígenas, etnomapas, como forma de representação simbólica, revelaram as espacialidades indígenas, seus lugares, seus anseios, reivindicações, experiências socioespaciais, preocupações com o equilíbrio ecológico, aspectos da cultura, um pouco de sua cosmogonia bem como da identidade e do território.

Os mapas são ricos em pictogramas, confirmando nossa hipótese de que os povos indígenas em Rondônia preferem representações pictóricas, especialmente para materialização da fauna e flora, que se mostram mais significativas na cultura indígena, o que confirma as ideias de Viveiros de Castro (2002). Com efeito, os pictogramas possuem duas faces, icônica e simbólica, e todas as imagens podem ser associadas a uma única ideia ou a ideias várias.

O exemplo mais recorrente foi a implantação do ícone que remete a um bovino. Esse pictograma remete à atividade econômica pecuária, que leva à retirada da vegetação e, por consequência, perda da fauna e diversas alterações no meio físico. Assim, a invocação desse símbolo reestrutura o fenômeno da exposição excessiva das terras indígenas, os impactos ambientais, o que assusta os povos indígenas. Confere o significado do que seja a pecuária em Rondônia, o que ela expõe ou o que ela suprime. Dessa forma, as simbologias se articulam e assumem significados no contexto em que ocorrem. Com isso, as representações indígenas devem ser concebidas no contexto de expropriação associada às transformações no espaço rondoniense.

Nesse sentido, constatou-se que as representações pictóricas restauraram a consciência coletiva e lhes "deram forma", por serem formas de representações sociais. Isso ocorre porque os mapeamentos sempre são estruturados de forma coletiva, onde os debates se acirram. Além disso, os mapas mentais podem funcionar como ancoragens, em uma perspectiva dialógica, pois classificam e dão nome a algumas coisas.

Os mapas resultaram também em objetivação, pois organizaram os elementos constituintes da representação e do percurso, por meio do qual tais elementos adquiriram materialidade, uma vez que se descobriu a qualidade icônica e reproduziu conceitos em uma imagem.

Essas representações gráficas são extremamente ricas e, por isso mesmo, seu uso pode ser variado. No que se refere ao ensino, o processo de mapeamento como reflexão coletiva instigou a produção de conhecimento entre as comunidades indígenas de Rondônia. Dinamizou a discussão dos problemas de cada terra indígena e como produto cartográfico 
pode ser utilizado no ensino de temas variados. Nesse sentido, admite-se que esse trabalho não esgotará as possibilidades, pois a análise do mapa reflete a experiência e a área do conhecimento de quem o analisa. Dessa maneira, um antropólogo observará aspectos que podem não ser percebidos por um biólogo, só para citar um exemplo.

Nos etnomapas predominaram pictogramas que lembraram animais, na maioria das vezes a anta (Tapirus), queixada (Tayassu tajacu), peixes e o boi. No entanto, o boi vem para evidenciar a influência da pecuária que ameaça a estabilidade das terras indígenas, especialmente pela retirada da vegetação, como referido. Ainda foi recorrente a representação pictográfica da flora: árvores, principalmente palmeiras e a castanha do Brasil (Bertholletia excelsa). Esses elementos do meio físico podem orientar estudos sobre a rica fauna e flora da Amazônia brasileira.

Além desses, foram recorrentes pictogramas que lembraram malocas (lugares tradicionais) e casas (lugares atuais, aldeias). Segundo Almeida Silva (2010, p. 74),

as antigas malocas, embora atualmente não habitadas, constituem-se nos centros referenciais de cerimoniais, em que se realizam os rituais sociais e espirituais e são referenciais territoriais para despertar sentimentos originais de reverências, medo, orgulho e alegria que se ampliam e multiplicam como fenômenos indispensáveis à identidade e ao pertencimento cultural.

Essas representações revelam que o modo de viver mudou com as influências de outras culturas.

Os mapas mentais elaborados revelaram a identidade de ser brasileiro na figura do "ser indígena" em Rondônia. A materialização dessa identidade ocorreu mediante a apresentação de seus adereços, seu cocar, sua pintura, sua pele amarela, seu alimento, sua cultura e seus conhecimentos. Assim, conhecemos os povos indígenas por aquilo que os caracterizam, pois as representações distinguem-se e contrapõemse aos modelos das sociedades envolventes. Essas representações ensinam que o "ser índio" não é imóvel, não é único, é extremamente diversificado, mesmo no espaço rondoniense. Dessa maneira, concordamos com a afirmação de Freire (2000) de que os indígenas não constituem um bloco único, com a mesma cultura, compartilhando as mesmas crenças, a mesma língua.

Nesse sentido, respeitando o tempo e o espaço determinados pelos rios, observouse uma intrínseca relação entre o ser índio e os recursos hídricos. A representação da água apareceu abundantemente nos mapas mentais, caracterizada como fonte de alimento e meio de circulação nas terras indígenas, e apresentou sentidos cosmológicos.

Os etnomapas revelaram que as florestas estão dispersas pelas terras indígenas, não sendo encontradas no seu exterior. Tal representação revelou que as comunidades indígenas vivem, ainda no século XXI, em "paz" com a floresta. No interior das florestas identificou-se a caça e, nos rios, a pesca, e fora delas, identificou-se o boi (a pecuária).

Outros pictogramas revelaram a paixão dos indígenas pelo futebol. Todas as representações espaciais das aldeias contemplaram ambientes para a prática desse esporte. Resultados semelhantes foram identificados nas pesquisas do Instituto Socioambiental (ISA) sobre os povos indígenas do Xingu no ano de 1996.

A interpretação quanto à especificidade dos ícones revelaram:

a. Representação dos elementos da paisagem natural: os elementos naturais do território e dos lugares foram recorrentes e em abundância no interior das terras indígenas, fato já mencionado.

b. Representação dos elementos da 
paisagem construída: da paisagem construída, chama-se atenção às aldeias que se formam de casas no estilo não indígena. Chama-nos atenção também a presença dos currais, que revelaram presença da pecuária fora das terras indígenas, mas também, em alguns casos, dentro das terras indígenas, já que alguns povos praticam a pecuária.

c. Representação dos elementos móveis: não se identificou uma clara representação dos fluxos, como os identificados por Lynch (1997). No entanto, os pictogramas que lembram as embarcações nos rios revelam o fluxo que ocorre, em algumas terras indígenas, unicamente pelas águas dos rios. d. Representação dos elementos humanos: elementos humanos são identificados por pictogramas que se diferenciam bastante, pois o indígena vem carregado de adereços utilizados por esses povos, enquanto o não indígena vem despido de adereços. Outras representações dos elementos humanos dizem respeito aos conflitos. O conflito é claramente mapeado pelas reivindicações de revisão das demarcações.

Da abordagem do conflito, destaca-se o mapa mental produzido pelos povos que vivem na Terra Indígena Pacaás Novos, localizada no extremo sul de Rondônia, divisa com a República da Bolívia (Figura 2).

Figura 2 - Terra Indígena Pacaás Novos. Destaque para a reivindicação de território na porção oeste, confluência do rio Guaporé com Rio Pacaás Novos.

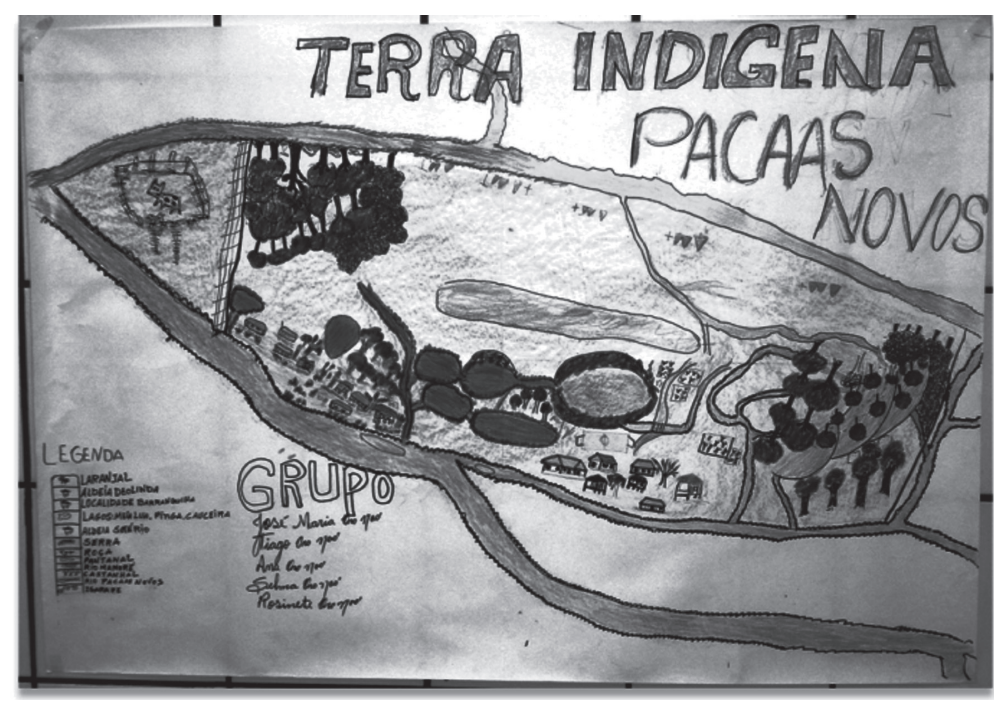

Fonte: Mapa elaborado por José Maria Oro Nao, Tiago Oro Nao, Ana Oro Nao, Selma Oro Nao e Resimere Oro Nao e publicado por Santos (2014).

O boi no curral do lado esquerdo do mapa revela que essa área, apesar de reivindicada pelos povos indígenas, ficou de fora do processo de demarcação dessa terra indígena. As cores distintas dos lagos revelam os ambientes que são invadidos pela comunidade envolvente para pesca predatória. A fiscalização que não existe e os limites não materializados, 
muitas vezes contribuem para a invasão das terras indígenas no estado de Rondônia. Os mapas indígenas também nos ensinam alguns aspectos do contato e das relações de parentesco. A professora indígena que elaborou o mapa apresentado na Figura 3 se preocupou em referendar como os indivíduos de sua aldeia se relacionam a partir do casamento.

Figura 3 - Etnomapa das relações de parentesco com destaque para um casal Macurap/Tupari. Terra Indígena Rio Guaporé, aldeia Ricardo Franco.

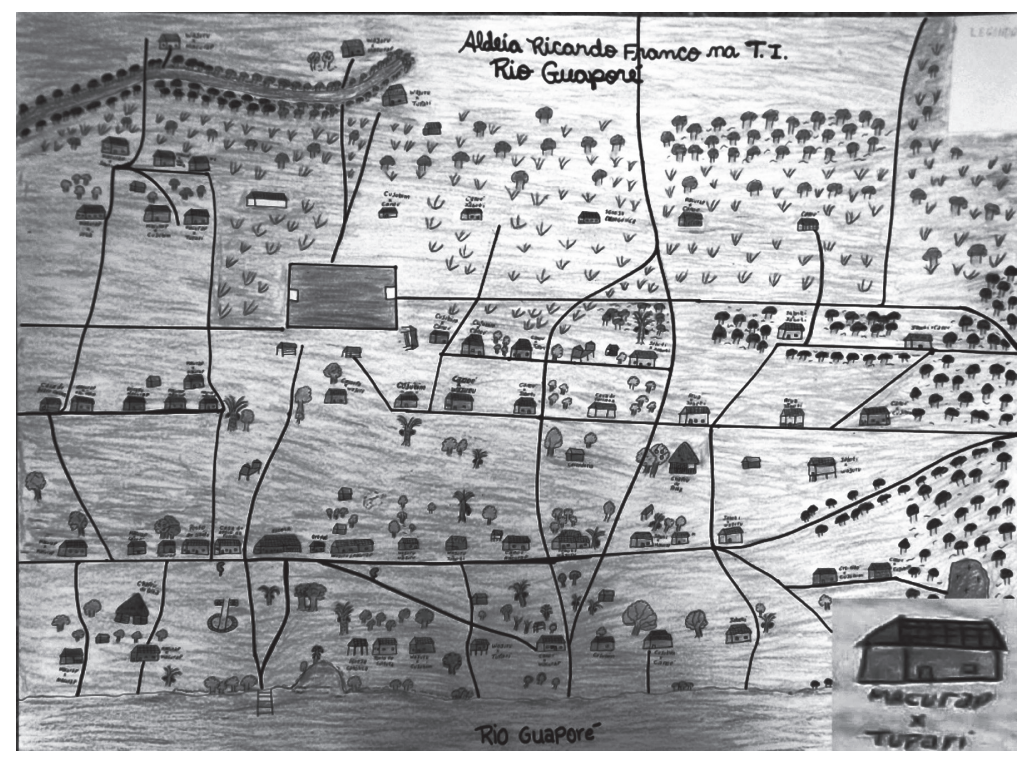

Fonte: Mapa elaborado por Maisa Makurap e publicado por Santos (2014).

Conforme o destaque para o pictograma (canto inferior direito) é possível observar que naquela casa vive um casal composto por indígenas das etnias Macurap e Tupari. $\mathrm{O}$ casamento entre povos revela aspectos do processo histórico do contato (VILAÇA, 2000; AZANHA; SÁ LEÃO, 2005; ARANHA, 2012). Ou seja, ao serem levados de seus territórios tradicionais para a porção oeste de Rondônia, onde se localiza a TI Rio Guaporé, os povos indígenas de diferentes culturas foram obrigados a conviver em terras indígenas comuns, a partir do "retalhamento" dos territórios. Essa interação "forçada" pelo processo de contato e ocupação resultou em casamentos interétnicos.

Dos recursos naturais, destaca-se o mapeamento dos seringais como lugares referenciados pelos povos indígenas. Alguns povos materializaram os seringais, mas a maioria não fez questão de representá-los. Essa representação insere-se nas discussões históricas, faz parte do passado do contato. Usam o seringal para narrar como o contato ocorreu. Para muitos trazem lembranças dolorosas de perdas de "parentes" (modo como os povos indígenas se referem uns aos outros). Na maioria das representações, a intenção foi revelar que o seringal é uma fonte de subsistência, pois o látex ainda é extraído por alguns povos.

Os castanhais são lugares que aparecem nas narrativas dos professores indígenas. Contudo, não é apenas uma árvore, pois têm significados múltiplos e, com isso, representaram também com o ouriço, que é o fruto da 
castanheira. Assim, a árvore é qualquer desenho,

(Figura 4). Dito de outra forma, a castanheira a castanheira é uma árvore, mas com o fruto não é apenas a árvore, é também o fruto.

Figura 4 - Espacialização das unidades de paisagem e recursos naturais na Terra Indígena Rio Branco.

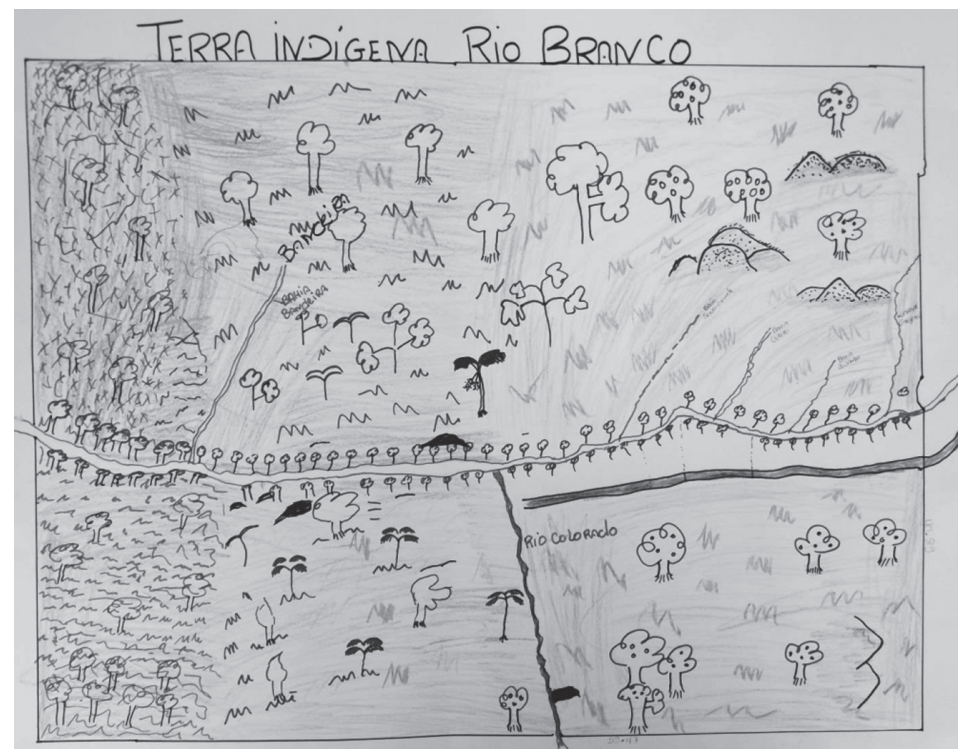

Fonte: Mapa elaborado por Alessandra Makurap e publicado por Santos (2014).

No período recente, os castanhais têm sido alternativa de renda para os povos indígenas. Nesse sentido, destacamos a produção extrativista do Noroeste de Mato Grosso eSudeste de Rondônia. Segundo o informativo do Projeto Pacto das Águas (ALVES, 2014), foi aprovada em assembleia a criação de uma cooperativa formada por povos indígenas, extrativistas e pelo projeto Pacto das Águas, desenvolvido com patrocínio da Petrobrás, para comercialização de castanha do Brasil (Bertholletia excelsa) e outros produtos florestais não madeireiros.

Uma das revelações dos etnomapas é o espaço geométrico, descrito por Dardel (2011) como aquele que valoriza o meio físico desprovido de vida humana. A representação revelou profundo conhecimento do meio físico da Terra Indígena Rio Branco, no sul de Rondônia (como exemplo para esta análise). Nessa área, a estudante Alessandra Macurap materializou três unidades de paisagem: área de inundação, área de transição e área de terra firme.

Assim como outros mapas mentais, o representado pela Figura 4 revela a geografia física do estado de Rondônia, que se compõe dessas três unidades de paisagem: terra firme, savanas e pantanais, inclusive, este último, com conectividade com o Pantanal Sul-MatoGrossense. Esse mapa mental pode ser explorado no ensino da temática em tela, inclusive como as características edafoclimáticas influenciam na dinâmica dos recursos hídricos, observados pelas cores variadas das águas.

Opantanal dosul (Figura 5a) da TIRioBranco apresenta riqueza florística e faunística singular. $\mathrm{O}$ exemplo disso é a possibilidade do contato com animais que não são tão facilmente identificados em outros ambientes, caso da anta (Tapirus terrestris) (Figura 5b), o maior mamífero terrestre do Brasil, mas já extinto em algumas áreas do país. 
Figura 5 - a) Pantanais no sul de Rondônia; e b). Anta no rio Branco, terra indígena Rio Branco, Estado de Rondônia.

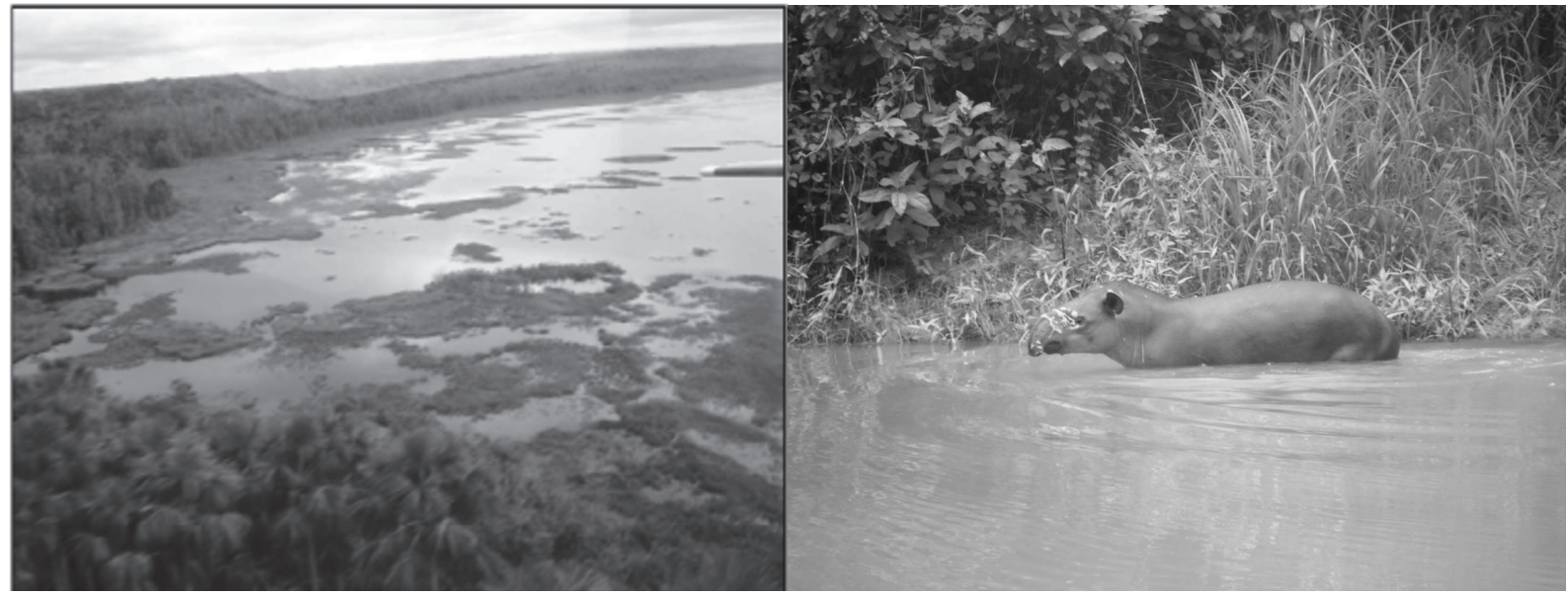

Fonte: Ferro (2015).

Além do exposto, foram espacializados na Figura 4 os principais rios: Branco, Colorado e Bandeira. Em todas as conversas com professores dessa terra indígena os rios referendados nos mapas também são lembrados.

A vegetação foi cuidadosamente implantada, de forma que foi possível perceber gramíneas em áreas periodicamente inundadas e áreas de florestas, com valorização da castanha do Brasil (Bertholletia excelsa). Os processos de mapeamento mostraram o quão profundo é o conhecimento dos povos indígenas sobre os rios, o relevo, as florestas e os animais mais encontrados nas terras indígenas e que tem mais significados para eles. Outro aspecto revelado pelos mapas indígenas foi a desterritorialização. Podemos assim afirmar que os povos indígenas foram desterritorializados e, no caso específico dos Gavião (Figura 6), foram mesmo enganados, como descrito por Nóbrega (2008). Nesse sentido, a desterritorialização a que nos referimos está ligada à "hibridização cultural que impede o reconhecimento de identidades claramente definidas - o território aqui é, antes de tudo, um território simbólico, ou um espaço de referência para a construção de identidades" (HAESBAERT, 2004, p. 35). 
Figura 6 - Reivindicação de parte do território Gavião no Estado do Mato Grosso.

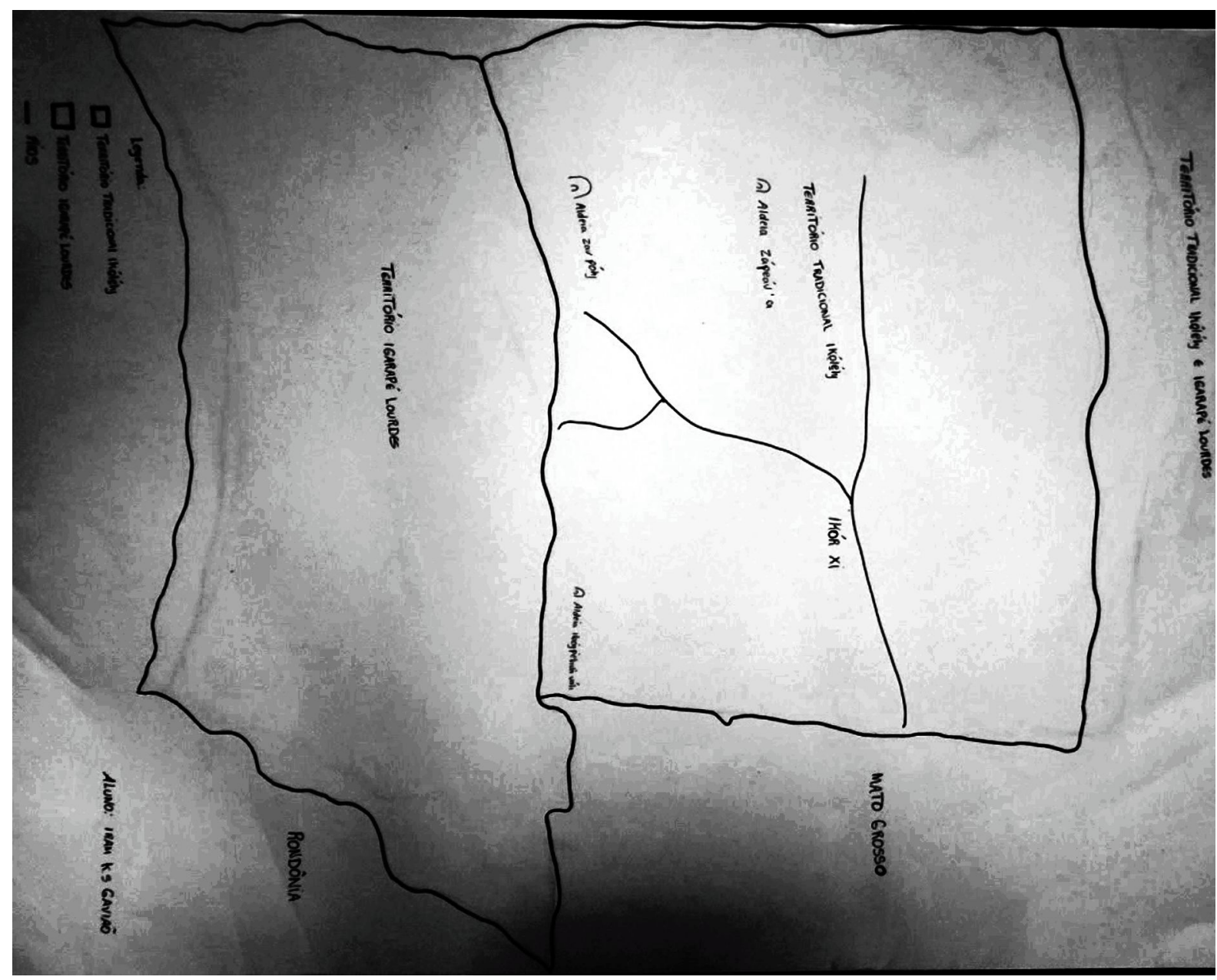

Fonte: Mapa elaborado por Iran Gavião e publicado por Santos (2014).

Nesse sentido, o professor da etnia Gavião materializou seu território reivindicado no Estado do Mato Grosso. No período atual, “o território reivindicado pelos Gavião está alterado, inúmeras são as fazendas que praticam a pecuária extensiva. Estradas de rodagem facilitam o fluxo pela área" (SANTOS, 2014, p. 268). Impactos socioambientais diversos decorrem do processo acelerado de ocupação.
Outro tema recorrente nos mapas mentais foi o impacto ambiental. Exemplo disso são os mapeamentos que materializaram a presença das usinas para obtenção de energia elétrica, a retirada da madeira, a pecuária e as queimadas. O mapa da Figura 7 é a síntese das preocupações, mas outros mapas trouxeram de forma clara os impactos associados aos diversos usos da paisagem. 
Figura 7 - Representação espacial dos impactos ambientais no entorno da TI 7 de Setembro.

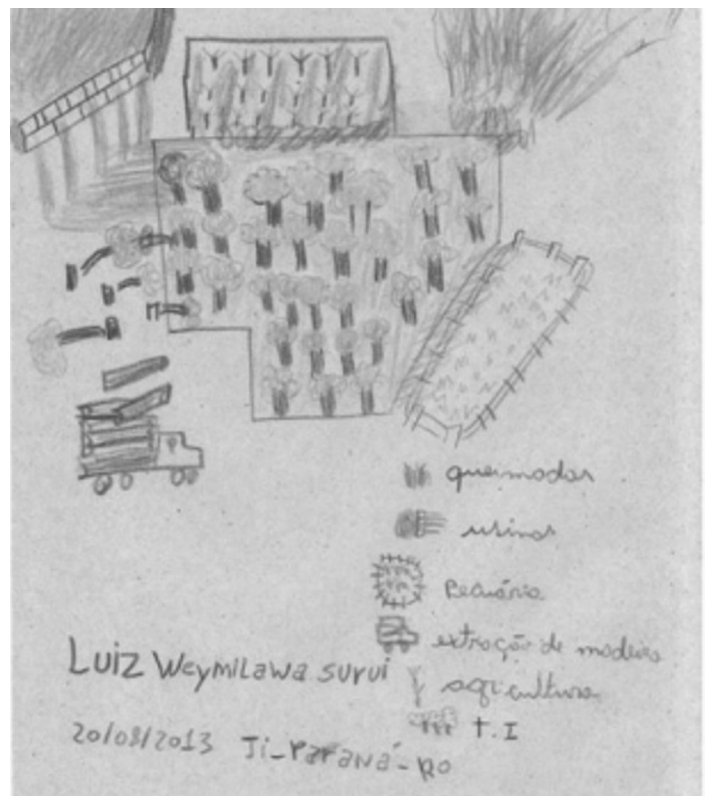

Fonte: Mapa elaborado por Luiz Weymilawa Suruí e publicado por Santos (2014).

A construção de barragens influencia na reprodução de espécies da fauna. Desse exemplo, destaca-se o relato que afirma que "os tracajás (Podocnemis unifilis), em alguns períodos do ano, quando ocorre o recuo das águas do rio devido o fechamento das comportas das usinas, saem para desovar, 'pensando' estar no período seco e de reprodução" (SANTOS, 2014, p. 179). Quando as comportas são abertas, as águas cobrem os ninhos e os ovos apodrecem.

O etnomapa falou por si e revelou as inquietações dos estudantes da etnia Suruí. Curioso foi o fato de que os impactos ocorreram no entorno, mas não dentro da terra indígena.

Outra análise possível a partir dos mapas indígenas foi aquela em função das cores. A representação pela cor foi destaque na pesquisa de Vidal (2011, p. 219), que realizou mapeamento simbólico das cores na sociedade indígena Kayapó-Xikrin do Bacajá, no sudoeste do Pará. Os resultados revelaram que as representações são polissêmicas, cujo significado só pode ser entendido em contextos específicos, e são carregadas de simbologias, "cujos significados variam segundo os contextos em apreço". Almeida (2005) ressaltou as cores utilizadas na representação dos rios no Acre. Naquele estado os indígenas coloriram os rios nos mapas mentais em amarelo. Observase, portanto, que a diferenciação na cor das águas dos rios refletiu a percepção da formação geológica dos rios da Amazônia.

De forma geral, os indígenas fizeram uso intenso das cores. A cor para alguns revelaram a relação com o meio, uma geograficidade da experiência. Com efeito, as cores dos rios chamam a atenção, pois marcam diferenças entre as etnias que merecem destaque. Os povos que vivem às margens do rio Guaporé representaram rios em cores não 
convencionais - preta, marrom e amarela. Ao contrário, a maioria dos povos mapearam os rios em tons variáveis de azul (uma aproximação com as convenções cartográficas, já que não se identificam rios com águas azuis em Rondônia). O volume e vazão do rio foram elementos determinantes para a diferenciação no tom de azul dos indígenas que vivem nas terras indígenas em Rondônia. Dessa forma, rios mais largos e com maior vazão receberam variações de azuis mais intensas, ao passo que os rios menores receberam tons mais fracos.

A variação da cor dos rios pode revelar que os indígenas destacaram seus conhecimentos da formação dos rios, uma vez que, na porção sul, estão associados às planícies de inundação que carreiam maior quantidade de material particulado em suspensão e, portanto, verifica-se uma diferença da cor das águas.

Nesse sentido, acredita-se que essa é uma das únicas discussões de que se tem conhecimento mais aprofundado, a aplicação da cor na representação indígena dos mapas mentais. A cor também é um artifício para representar o antrópico ou área desmatada ou desflorestada. A pastagem normalmente não tem pictograma que a represente enquanto vegetação. Normalmente receberam cores marrons, possivelmente por representar a ausência de vida. A cor verde, sempre associada aosaspectosnaturais da paisagem, secontrapõeàs cores como marrom, como referido, o antrópico.

Por fim, destacam-se a materialização de escala, fluxos e variação das representações no tempo. Nesse sentido, diversas pesquisas já revelaram que a escala cartográfica nãoé aplicada aos mapas mentais. Por isso, eles não receberam o devido valor, fato já mencionado por Harley (1991). No entanto, essa nãoé a única abordagem de escala possível. Dardel (2011) sugeriu em sua obra, como já referido, que as distâncias são experimentadas não como uma quantidade, mas como uma qualidade. Além disso, Castro (2003) afirma que a escala é, na realidade, medida que confere visibilidade ao fenômeno.

Assim, é possível indicar a valorização de um lugar em detrimento de outro e, com isso, o superdimensionamento de um signo em detrimento de outro. Isso ocorre com muita frequência nos mapas mentais, especialmente quando são elaborados no contexto de alguma discussão específica. Além da escala, outra questão relacionada aos mapas mentais foi saber se os mesmos materializaram fluxos. Os resultados revelaram pouca expressão do fluxo, a não ser de automóveis na BR-364, na retirada da madeira do interior da terra indígena (Figura 6), e de animais nos rios. No entanto, não se identificou uma simbologia, setas, por exemplo, para revelar movimentos.

\section{Considerações finais}

As representações através dos mapas mentais apresentaram particularidades e singularidades que autorizam denominá-las de cartografias indígenas de Rondônia. Além disso, observaram-se potencialidades no ensino e reconhecimento dos conflitos, reinvindicações do território, relações de parentesco, estudos do meio físico, impactos ambientais sobre as terras indígenas e sobre a fauna e flora.

Dessa maneira, a compilação e reprodução dos mapas mentais podem ser aplicadas a produção de material didático para apoio ao ensino de temas variados nas escolas indígenas. Essas possibilidades foram sugeridas aos professores indígenas que participaram das pesquisas.

Da metodologia é fundamental compreender que as análises a partir dos mapas mentais não se esgotam neste trabalho, pois apesar da metodologia robusta, as possibilidades são amplas nas áreas de antropologia, geografia, biologia e história, como por exemplo.

As representações espaciais indígenas 
são polissêmicas, não estão comprometidas com regras rígidas de Cartografia e padronizações cartográficas nos moldes aceitos por uma parte da comunidade científica, mas é igualmente rica e apresenta potencial na análise dos temas abordados. Essa valorização do produto cartográfico indígena de Rondônia é uma valorização dos saberes tradicionais, uma forma de dar voz e visibilidade aos anseios dessas comunidades.

\section{Referências}

ACSELRAD, H.; COLI, L. R. Disputas cartográficas e disputas territoriais. In: ACSELRAD, H. Cartografias sociais e território. Rio de Janeiro: Universidade Federal do Rio de Janeiro, Instituto de Pesquisa e Planejamento Urbano e Regional, 2008. p. 13-44.

ALMEIDA, R. A. A Cartografia na Agenda 21 das terras indígenas do Estado do Acre. In: ENCONTRO DE GEÓGRAFOS DA AMÉRICA LATINA, 10., 2005, São Paulo. Anais... São Paulo: UNIVERSIDADE DE SÃO PAULO, 2005. p. 496-521.

ALMEIDA, A. Territorialidades e identidade dos coletivos Kawahib da Terra Indígena UruEu-Wau-Wau em Rondônia: "Orevaki Are" (reencontro) dos "marcadores territoriais". 2010. 301 f. Tese. (Doutorado em Geografia) - Setor Ciências da Terra, Departamento de Geografia, Universidade Federal do Paraná, Curitiba, 2010.

ALVES, A. L. Pacto das Águas. Informativo do Projeto Pactos das Águas, 2014. Disponível em: <http://pactodasaguas.org.br/pt/biblioteca/revistas.33.html>. Acesso em: 14 jun. 2016.

ARANHA, P. M. Levantamentos territoriais e construção de saberes geográficos na Comissão de Linhas Telegráficas Estratégicas do Mato Grosso ao Amazonas (1907-1915). Revista Brasileira de História da Ciência, Rio de Janeiro, v. 5, n. 1, p. 91-100, jan./jun., 2012.

ARCHELA, R. S; ARCHELA, E. Correntes da cartografia teórica e seus reflexos na pesquisa. Geografia, Londrina, v. 11, n. 2, p. 161-170, jul./dez., 2002. Disponível em: <http://www.uel.br/revistas/uel/ index.php/geografia/article/view/6721>. Acesso em: 14 jun. 2016.

AZANHA, G.; SÁ LEÃO, M. A. C. "Karipuna". In: Enciclopédia Virtual Povos Indígenas no Brasil.

São Paulo. Instituto Socioambiental. Disponível em: <https://pib.socioambiental.org/pt/povo/ karipuna-de-rondonia >. Acesso em: 21 fev. 2014.

BELYEA, B. Amerindian maps: the explorer as translator. In: Journal of Historical Geography, London, v. 18, n. 3, 1992. p. 267-277. doi: https://doi.org/10.1016/0305-7488(92)90203-L.

CASTRO, I. E. O problema da escala. In: CASTRO, I. E.; GOMES, P. C. C.; CORRÊA, R. L. (Orgs.). Geografia: conceitos e temas. Rio de Janeiro: Bertrand Brasil, 2003. p. 59-94.

CASTRO AGUIRRE, C. Elementos de metodología descriptiva para el análisis espacial. Lurralde: Inv. Espac., San Sebástian, n. 5, p. 409-471, 1982.

. Mapas cognitivos: que son y cómo explorarlos. Scripta Nova, Barcelona, n. 33, fev. 1999.

Disponível em: <http://www.ub.edu/geocrit/sn-33.htm>. Acesso em: 13 dez. 2016. 
CHAPIN, M.; LAMB, Z.; THRELKELD, B. Mapping indigenous land. Annual Review of Anthropology, Palo Alto, v. 34, p. 619-638, 2005. Disponível em: <http://www.annualreviews. org/doi/pdf/10.1146/annurev.anthro.34.081804.120429>. Acesso em: 25 abr. 2014. doi: https:// doi.org/10.1146/annurev.anthro.34.081804.120429.

CORREIA, A. C. S.; SÁ, L. A. C. M. Estudo teórico sobre mapas cognitivos para geração de bases de dados espaciais. Revista Brasileira de Cartografia, Rio de Janeiro, v. 61, n. 3, 2009, p. 245-259, 2009. Disponível em: <http://www.rbc.lsie.unb.br/index.php/rbc/article/view/281/270>. Acesso em: 12 nov. 2016.

DARDEL, E. O homem e a Terra. Tradução Werther Holzer. São Paulo: Perspectiva, 2011. 176 p.

FERRO, P. D. Análise da dinâmica espaço-temporal da cobertura vegetal e zona de amortecimento do Parque Estadual de Corumbiara-RO. 2015. 57 f. Trabalho de Conclusão de Curso (Especialização em Geoprocessamento Ambiental) - Instituto Federal de Educação, Ciência e Tecnologia, Colorado do Oeste, 2015.

FREIRE, J. R. B. Cinco ideias equivocadas sobre o índio. In: Revista do Centro de Estudos do Comportamento Humano, Manaus, n. 1, p. 17-33, set. 2000.

GAVAZZI, R. A. Agrofloresta e cartografia indígena: a gestão territorial e ambiental nas mãos dos agentes agroflorestais indígenas do Acre. 2012. 297 f. Dissertação (Mestrado em Geografia) Departamento de Geografia da Faculdade de Filosofia, Letras e Ciências Humanas, Universidade de São Paulo, São Paulo, 2012.

HAESBAERT, R. O mito da desterritorialização: do "fim dos territórios" à multiterritorialidade. Rio de Janeiro: Bertrand Brasil, 2004. 395 p.

HARLEY, J. B. A nova história da cartografia. O Correio da UNESCO, São Paulo, n. 8, p.1-5, 1991. Disponível em: <https://geolivros.noblogs.org/gallery/5452/a_nova_historia_da_cartografia-harley. pdf $>$. Acesso em: 17 set. 2016.

KASHIWAGI, H. M. Representações da paisagem no Parque Nacional de Superagui: a homonímia sígnica da paisagem em áreas preservadas. 2011. 275 f. Tese (Doutorado em Geografia) - Departamento de Geografia, Universidade Federal do Paraná, Paraná, 2011.

KOZEL, S. Mapas mentais: uma forma de linguagem. Perspectivas metodológicas. In: KOZEL, S.; COSTA E SILVA, J.; GIL FILHO, S. F. (Orgs.). Da Percepção e cognição à representação: reconstruções teóricas da geografia cultural e humanista. São Paulo: Terceira Margem, 2007, p.114138.

LYNCH, K. A imagem da cidade. Tradução de Jefferson Luiz Camargo. São Paulo: Martins Fontes, 1997. 227 p.

LOCH, R. E. N., FUCKNER, M. A. Do ensino de cartografia na universidade à cartografia que se ensina na educação básica. In: CONGRESSO BRASILEIRO DE CARTOGRAFIA. 21., 2003. 
Belo Horizonte. Anais.... Disponível em: <http:/www.cchla.ufrn.br/geoesp/arquivos/artigos/ ArtigoAmbienteEnsinoCartografia3.pdf>. Acesso em: 21 ago. 2016.

MENDONÇA NETO, O. A cartografia inovadora: uma reflexão sobre a cartografia social - Ciência ou arte? In: ENCONTRO DE GEÓGRAFOS DA AMÉRICA LATINA, 14., 2013. Lima. Anais... Disponível em: <http://www.egal2013.pe/wpcontent/uploads/2013/07/Tra_Ozimo-Mendon\%C3\%A7a-Neto. pdf $>$. Acesso em: 21 jun. 2016.

MOORE, G. T. El desarrollodel conocimiento del ambiente: revisión de la teoría constructicionista interacionaly alguns datos sobre las variaciones evolutivas intraindividuales. Revista Estudios de Psicología, Madrid, n. 14/15, p. 109-123, 1983.

NÓBREGA, R. S. Contra as invasões bárbaras, a humanidade: a luta dos Arara (Karo) e dos Gavião (Ikólóéhj) contra os projetos hidrelétricos do Rio Machado, em Rondônia. 2012. 205 f. Dissertação (Mestrado em Sociologia) - Instituto de Filosofia e Ciências Humanas, Universidade Estadual de Campinas, Campinas, 2012.

OLIVEIRA, L. Estudo metodológico e cognitivo do mapa. 1978. 128 f. Tese (Doutorado em Geografia) - Faculdade de Filosofia, Letras e Ciências Humana, Universidade de São Paulo, São Paulo, 1978.

Ainda sobre percepção, cognição e representação em geografia. In: MENDONÇA, F.; KOZEL, S. Elementos de epistemologia da geografia contemporânea. Curitiba: Editora da UFPR, 2009.

RICHTER, D. O mapa mental no ensino geografia: concepções e propostas para o trabalho docente. São Paulo: Cultura Acadêmica, 2011. 272 p.

RUNDSTROM, R. Mapping, postmodernism, indigenous people and the changing direction of North American cartography. Cartographica, Toronto, n. 28, v. 1, 1991. Disponível em: < http:// www.utpjournals.press/doi/10.3138/5J46-51T2-7M42-316G>. Acesso em: 12 jul. 2016. doi: https://doi.org/10.3138/5J46-51T2-7M42-316G.

SANTOS, A. M. Cartografias dos povos e das terras indígenas em Rondônia. 2014. 314 f. Tese (Doutorado em Geografia) - Setor Ciências da Terra, Departamento de Geografia, Universidade Federal do Paraná, Curitiba, 2014.

SIMÕES, D. A trindade no conhecimento: uma leitura semiótica libertária. In: HENRIQUES, C. C.; SIMÕES, D. (Orgs.). A redação de trabalhos acadêmicos: teoria e prática. 6. ed. Rio de Janeiro: EdUERJ, 2014. 134 p.

TUAN, Yi-Fu. Espaço e lugar: a perspectiva da experiência. São Paulo: Difel, 1983. 248 p.

VIDAL, L. B. O mapeamento simbólico das cores na sociedade indígena Kayapó- Xikrin do Sudoeste do Pará. In: SILVA, A. L.; FERREIRA, M. K. L. Antropologia, história e educação: a questão indígena e a escola. 2. ed. São Paulo: Global, 2001. 396 p.

VILAÇA, A. O que significa tornar-se outro? Xamanismo e contato interétnico na Amazônia. Rev. Bras. Ci. Soc., São Paulo, v. 15, n. 44, out. 2000. Disponível em: < http://www.scielo.br/ 
pdf/rbcsoc/v15n44/4147.pdf>. Acesso em: 14 set. 2013. doi: http://dx.doi.org/10.1590/S010269092000000300003.

VIVEIROS DE CASTRO, E. B. O nativo relativo. Mana, Rio de Janeiro, v. 8, n. 1, p. 113148, abr. 2002. Disponível em: < http://www.scielo.br/scielo.php?script=sci_arttext\&pid =S0104-93132002000100005 $>$. Acesso em 18 jul. 2016. doi: http://dx.doi.org/10.1590/S010493132002000100005.

Submetido em 15 de outubro de 2016.

Aprovado em 17 de abril de 2017. 